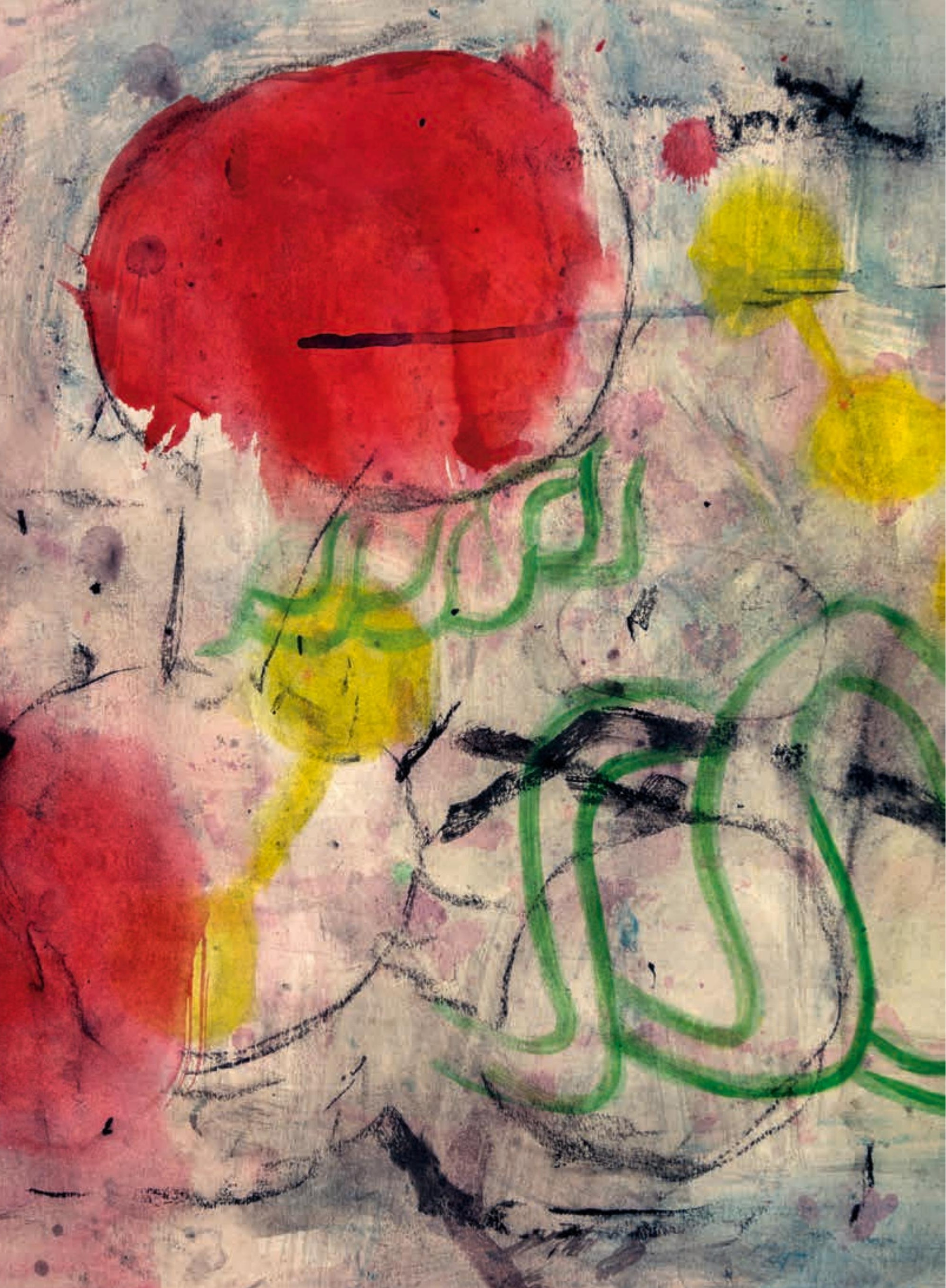




\title{
\#Biotech
}

\section{The need for biotechnology communication}

\author{
Monograph coordinated by Lluís Montoliu
}

T

he communication of biotechnology has played a key role in recent years. The great advances made and the speed with which new genetic editing techniques are implemented raise enormous expectations but also concerns. Good communication of the application of biotechnology in different fields - medicine, agriculture, industry - must be accompanied by a constant dialogue between scientists and society.

The idea of this monograph came from the II Conference of the Association of Biotechnology Communicators (AcB in its Spanish initialism), of which I am a member. It was held in Valencia a couple of years ago, and some of the topics that aroused the most interest, debate and participation - such as the constant flow of new information about CRISPR, animal experimentation or the importance of understanding what information a DNA analysis can provide - have served as the basis for some of the documents in this issue. Others, such as the public perception of biotechnology and the importance of the use of metaphors to explain some biotechnological processes, complete this multifaceted view of communication and biotechnology.

Lluís Montoliu. CSIC scientific researcher in the Department of Cellular and Molecular Biology at the National Centre for Biotechnology (CNB-CSIC) and the CIBER of Rare Diseases (CIBERER-ISCIII), Madrid (Spain). His team was pioneering in Spain in its use of CRISPR tools to research rare human diseases such as albinism using animal models. In 2006, he founded the International Society for Transgenic Technologies (ISTT), which he presided over until 2014. He is currently the President of the European Society for Pigment Cell Research (ESPCR) and a member of the CSIC ethics committee and the ethics board of the European Research Council (ERC). $\square$ montoliu@cnb.csic.es

Illustrating this monograph are the works of the artist Jorge Carla (Madrid, 1974), who, through shapes and colour stains, explores and reflects on the aspects of biotechnology that are most suggestive to him.

Jorge Carla. Composition with two green helices, 2018 . Mixed technique on paper, $43 \times 50 \mathrm{~cm}$. 